\title{
Colorectal cancer and screening awareness and sources of information in the Hungarian population
}

\author{
Noémi Gede ${ }^{1 *}$, Diána Reményi Kiss ${ }^{2}$ and István Kiss ${ }^{3}$
}

\begin{abstract}
Background: This study aims to survey the level of awareness of colorectal cancer and screening and to identify sources of information among the population under investigation.

Methods: A cross-sectional study was conducted among 1150 adults between the ages of 40 and 70 using quota sampling. Data were collected through self-made questionnaires to be completed by respondents.

Results: $32.7 \%$ of the participants correctly identified the recommended beginning of colorectal cancer screening, these participants were more likely to see their physician more frequently in the past years than those answering to the qusetion incorrectly $(p=0.008)$. $22.4 \%$ of the respondents were in possession of appropriate information on the frequency of colorectal cancer screening and had a relatively high level of educational attainment $(p<0.001)$. Very few respondents were well-informed about the risk factors and symptoms of colorectal cancer. Those who were well-informed were likely to live in a county town $(p<0.001)$ and to have a relatively high level of educational attainment $(p<0.001$ ). They were most likely to have accessed their information on the internet. $27.0 \%$ of respondents had not heard of CRC screening methods before. They were likely to be male and relatively young and to have a relatively low level of educational attainment. Furthermore, they saw their doctor relatively seldom. The respondents who had heard about screening methods were most likely to have gathered their information from health workers. Conclusions: The majority of respondents did not have sufficient information about colorectal cancer and screening. This is particularly true of less educated, younger male participants who do not live in a county town and of respondents who see their physician relatively seldom. Sources of information should be used more effectively, thus yielding an increased level of awareness.
\end{abstract}

Keywords: Colorectal cancer, Cross-sectional, Awareness, Screening, Prevention

\section{Background}

Colorectal cancer (CRC) was the fourth leading cause of cancer death worldwide in 2012. Incidence of CRC was more than 8500 in Hungary in 2012, and mortality was nearly 4500 [1]. In 2013, from among the 28 member states of the European Union, the highest standardised death rate could be found in Hungary, followed by Slovakia [2]. In Hungary, CRC is most commonly recognized at a late stage, when options for curative care are limited [3].

\footnotetext{
* Correspondence: gede.noemi@gmail.com

${ }^{1}$ Institute for Translational Medicine, Medical School, and Doctoral School of Health Sciences, Faculty of Health Sciences, University of Pécs, Szigeti út 12, Pécs 7624, Hungary

Full list of author information is available at the end of the article
}

CRC has several risk factors, of which the most important are the following: obesity, a sedentary lifestyle, smoking, excessive consumption of alcohol and red meats, a low-fibre, high-fat diet, a positive family history and age (over 50) [4-6].

The aims of screening are to reduce the risk of death from CRC through early detection and the occurrence of complications associated with detection of cancer at a later stage. Such screening also purposes to decrease the incidence and mortality of CRC by detection and removal of precancerous lesions [7]. According to a meta-analysis, faecal occult blood testing (FOBT) and sigmoidoscopy screening yielded a reduction of 18 and $26 \%$ in CRC mortality, and reduction of 8 and $27 \%$ in late-stage CRC incidence respectively [8]. 
The two-stage screening method is used in Hungary in accordance with the recommendations of the Chief Medical Officer of Hungary. In people of average risk, FOBT should be carried out biannually, and, in the case of a positive test result, a colonoscopy should be performed [9]. It should be noted that only opportunistic CRC screening programmes were conducted before 2017. Colorectal screening has been conducted nationwide since then, like cervical and breast cancer screenings. Awareness among laypeople about CRC (i.e., risk factors and symptoms) and CRC screening has proved to be insufficient; only about $21-44 \%$ of the participants in the relevant studies exhibited appropriate knowledge of CRC screening [10-14]. Many reports have shown a significant relationship between awareness and willingness to participate. Being well-informed has a positive effect on participation in CRC screening [15-17]. However, participation in CRC screening is very low in Hungary [18]. Low rates can also be observed in various other countries, $[19,20]$ but efforts are being made to improve the situation [21, 22]. A comprehensive and representative report on people's awareness has not yet been drafted in Hungary. The lack of such a report may be one of the main reasons for avoidance of CRC screening. This study aims to survey level of awareness and to ascertain sources of information among the population under investigation.

\section{Methods}

The study was conducted in 23 general practitioner districts in Baranya County in southwestern Hungary from 2015 to 2016. Surveys were administered within a few weeks in each site of sampling. Sites collected the data within three working days per week, the proportion of morning and afternoon office hours was 1 to 1 .

\section{Participants}

1150 people between the ages of 40 and 70 were recruited using quota sampling. Participants were included by observing the distribution by sex and place of residance reported in the database of Hungarian Central Statistical Office. The exclusion criterion was a diagnosed cancerous disease. 138 people were excluded because of a lack of responses. Consequently, data from 1012 participants $(88.0 \%)$ were evaluated. Data were collected through self-made questionnaires to be completed by respondents in the waiting room of their general practitioner. The questionnaires and written informed consent forms were distributed by assistants in the waiting room and proper time was given to decide whether to participate in the study. All participants remained anonymous in this study. Ethical approval was received from the Regional and Institutional Ethical Committee of the University of Pecs, Hungary.

\section{Questionnaire survey}

Age, sex, place of residence, educational attainment, financial situation and religiosity were surveyed. The respondents assessed their financial situation on a Likert scale ranging from very poor $(=1)$ to very good $(=5)$.

Similarly, they answered certain multiple-choice questions, such as recommended beginning, frequency and protocol of CRC screening, and importance of early detection and asymptomatic development of CRC. The participants assessed their knowledge of CRC screening, and at the end of the questionnaire they were provided the opportunity to decide whether they wished to receive more information. The study surveyed knowledge of CRC screening methods, risk factors and symptoms, and sources of information. Participants were able to provide multiple responses to all these questions. The responses to some of the questions were reduced to dichotomous variables for the sake of extensive analysis. Respondents who chose six correct symptoms and no more than one incorrect symptom or five correct symptoms without incorrect symptoms were regarded as well-informed, and all other respondents were evaluated as not being well-informed. Respondents who chose eight correct risk factors and no more than one incorrect risk factor or seven correct symptoms without incorrect symptoms were regarded as well-informed, and everybody else was seen as not being well-informed (Additional file 1).

\section{Statistical analyses}

The analysis was performed with descriptive statistics mean, median and relative frequency - a goodness-of-fit $\chi^{2}$ test, binominal and one-sample median tests, odds ratio, the Kruskal-Wallis test with the Mann-Whitney test as a post hoc test and the Bonferroni correction. A two-sided $p$ value of $<0.05$ was regarded as statistically significant.

The available-case analysis was used for missing data. Statistical analyses were performed with SAS software version 9.2 (SAS Institute Inc., Cary, NC).

\section{Results \\ Sample characteristics}

The socio-demographic characteristics of the sample are provided in Table 1. The data for the population under investigation were compared to data for Baranya County at the Hungarian Central Statistical Office. Based on the comparison, the sample is representative with respect to age $(p=0.462)$, sex $(p=0.745)$ and place of residence $(p$ $=0.846) .0 .9 \%$ of the respondents had received less than a primary school education, $11.8 \%$ had completed primary school, $31.0 \%$ had earned a vocational school certificate, $39.1 \%$ had a secondary school education, and $17.2 \%$ had received a college/university degree. Participants rated their financial situation as follows: very poor 
Table 1 Socio-demographic characteristics in terms of representativeness

\begin{tabular}{llll}
\hline & & Population $(N=1012)$ & Hungarian Central Statistical Office $(N=159,758)$ \\
\hline Age & Mean & 54.4 & 54.4 \\
& Median & 55 & 55 \\
Sex & Male & $N(\%)$ & $N(\%)$ \\
Place of residence & Female & $470(46.4 \%)$ & $75,086(47.0 \%)$ \\
& County town & $542(53.6 \%)$ & $84,672(53.0 \%)$ \\
& Other town & $395(39.0 \%)$ & $61,028(38.2 \%)$ \\
& Village & $266(26.3 \%)$ & $42,176(26.4 \%)$ \\
\end{tabular}

(3.8\%), poor (17.5\%), acceptable (45.4\%), good (30.5\%) and very good $(2.8 \%)$. $52.3 \%$ of the respondents were religious.

Awareness of guideline and importance of CRC screening $32.7 \%$ of the participants knew the recommended beginning of colorectal cancer screening. $22.4 \%$ of the respondents provided correct answers about the required frequency of CRC screening, 59.2\%, knew the CRC screening protocol, 69.6\% were aware that early-stage CRC is a curable disease, and $56.2 \%$ understood that there is an asymptomatic period in the development of CRC. Participants who knew the recommended beginning of colorectal cancer screening were more likely to see their physician more frequently in the past years than those answering to the qusetion incorrectly $(p=0.008)$. Patients providing a correct answer about required frequency, protocol, curability of early stage CRC, and asymptomatic period of CRC had significantly higher levels of educational attainment as compared to those providing a wrong answer $(p<0.001, p<0.001, p=0.009$ and $p<0.001$, respectively).

\section{Awareness of CRC screening methods}

The respondents indicated which screening methods they had heard of. These distributions are provided in percentage form in Fig. 1. Those who had not heard about CRC screening methods were likely to be male $(\mathrm{OR}=1.71 ; 95 \% \mathrm{CI}: 1.29-2.26)$ and relatively young $(p=$ $0.002)$; they had a relatively low level of educational attainment $(p<0.001)$ and saw their physician relatively seldom $(p<0.001)$.

\section{Awareness of CRC risk factors and symptoms}

$18.8 \%$ of the respondents were well-informed about the risk factors of CRC, and $81.2 \%$ were not. $21.0 \%$ were well-informed about the symptoms of CRC, and $79.0 \%$ were not. Those who were well-informed were likely to live in a county town $(p<0.001)$ and have a relatively high level of educational attainment $(p<0.001)$. 14.1\% had a positive family history for CRC, but only $53.0 \%$ of those considered family history a risk factor.

\section{Sources of information about CRC}

The participants indicated their source of information about CRC. These distributions are provided in percentage form in Fig. 2. There is a significant relationship

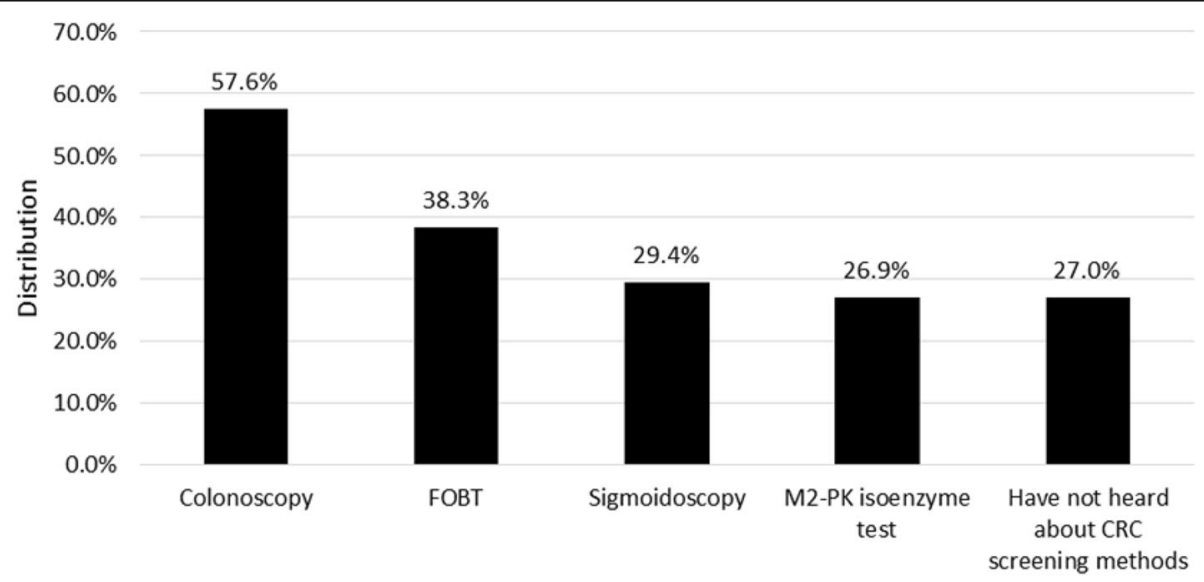

Fig. 1 Awareness of CRC screening methods. CRC: Colorectal Cancer FOBT: Faecal Occult Blood Test M2-PK: pyruvate kinase isoenzyme type M2 


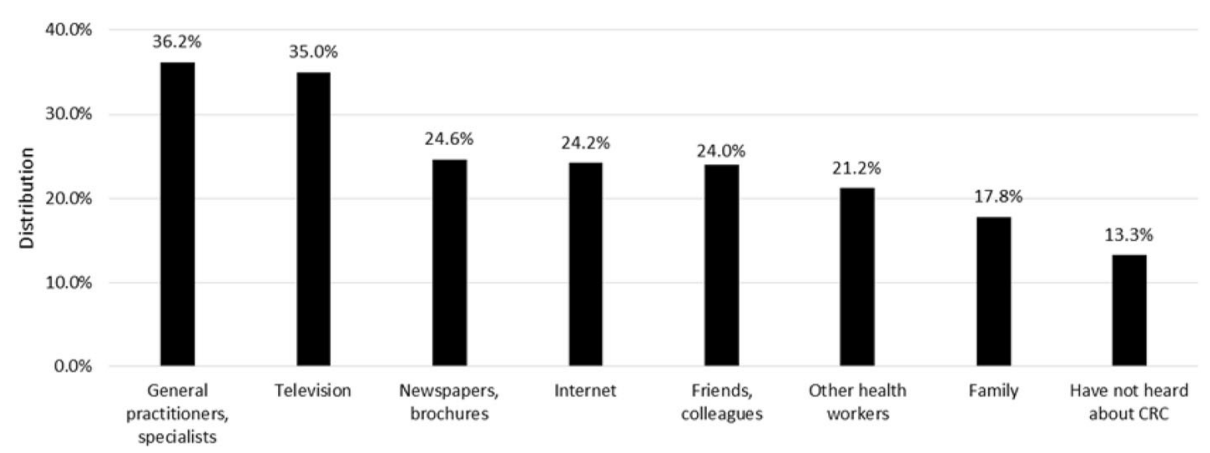

Fig. 2 Sources of information about CRC. CRC: Colorectal Cancer

between the sources of information indicated and knowledge about CRC and screening; socio-economic characteristics are provided in Tables 2 and 3. Patients who had never heard about CRC saw their physician less frequently $(p<0.001)$.

\section{Judgement of the level of awareness}

$26.0 \%$ of the population under investigation thought that their knowledge about CRC screening was appropriate. They were less likely to have a relatively high level of educational attainment $(p<0.001)$, and they were females $(\mathrm{OR}=1.52$; 95\% CI: $1.14-2.02) .67 .4 \%$ wanted to obtain more information about CRC screening. These respondents were likely to be religious (OR $=1.52$; 95\% CI: 1.17-1.99) and they had not heard of CRC screening before $(\mathrm{OR}=1.68$; 95\% CI: $1.26-2.25)$.

\section{Discussion}

$32.7 \%$ of the participants knew the recommended beginning of colorectal cancer screening. In similar cross-sectional studies, this rate was more favourable (47.9\%; 83.0\%) [23, 24]. These respondents were likely to see their physician more frequently. Furthermore, $22.4 \%$ of the participants knew the frequency of CRC, $59.2 \%$ had accurate information about protocol, and $56.2 \%$ were informed about the development of CRC. $69.6 \%$ of the respondents knew the importance of early detection. A previous report, however, showed a better rate (78.5\%) [25]. Those people who had suitable information about the frequency and protocol of CRC screening and its importance were likely to have a relatively high level of educational attainment.

The most frequently mentioned screening methods were colonoscopy and FOBT. 27.0\% of the participants had not heard about CRC screening methods before. Berkowitz et al. also surveyed respondents who had not heard of CRC screening methods, and, compared to our study, their rate was higher (42.0\%) [26]. They were likely to be relatively young males who had a relatively low level of educational attainment and saw their physician relatively seldom.

$81.2 \%$ of the respondents were not well-informed about the risk factors. In a previous study, this rate was more than $90.0 \%$ [27]. Furthermore, merely $53.0 \%$ of the participants with a positive family history for CRC considered heredity a risk factor. $79.0 \%$ of the respondents were not well-informed about the symptoms. In the study just noted, this rate was over 90.0\% [27]. Both studies showed that higher education affects awareness positively, but our study found that the place of residence also had a significant effect on awareness.

Sources of information were as follows: general practitioners or specialists (36.2\%), television (35.0\%), newspapers and brochures (24.6\%), internet $(24.2 \%)$, friends or colleagues (24.0\%), other health workers $(21.2 \%)$ and family (17.8\%). A small proportion of respondents (13.3\%) had never heard about CRC before. This rate was higher in a cross-sectional study (22.0\%) [28]. In an Italian report, this order was different from the results of our study: (1) friends, (2) television, (3) newspapers, (4)

Table 2 Relationship between source of information and socio-economic characteristics

\begin{tabular}{lll}
\hline Source of information & Socioeconomic characteristics & $P$ value \\
\hline General practitioners, specialists & Users are older & $p<0.001$ \\
Internet & Users are younger & $p<0.001$ \\
& Users have better financial situation & $p=0.001$ \\
Newspapers, brochures & Users are older & $p=0.046$ \\
I have never heard about CRC & Users are younger & $p=0.010$ \\
\hline
\end{tabular}

A user is a person who answered YES to the question about using that specific source of information in the questionnaire 
Table 3 Relationship between source of information and awareness of CRC and screening

\begin{tabular}{lll}
\hline Source of information & Information about CRC and screening & odds ratio \\
\hline General practitioners, specialists & Users were likely to have heard about FOBT & OR $=3.61 ; 95 \%$ Cl: $2.76-4.73$ \\
& Users were likely to have heard about the M2-PK isoenzyme test & OR $=2.32 ; 95 \%$ Cl: $1.74-3.08$ \\
& Users were likely to have heard about colonoscopy & OR $=2.77 ; 95 \%$ Cl: $2.10-3.66$ \\
Other health workers & Users were likely to have heard about FOBT & $\mathrm{OR}=3.60 ; 95 \% \mathrm{Cl}: 2.63-4.93$ \\
& Users were likely to have heard about the M2-PK isoenzyme test & $\mathrm{OR}=2.49 ; 95 \% \mathrm{Cl}: 1.81-3.42$ \\
& Users were likely to have heard about colonoscopy & $\mathrm{OR}=2.41 ; 95 \% \mathrm{Cl}: 1.72-3.36$ \\
Internet & Users were likely to be well-informed about risk factors & $\mathrm{OR}=3.32 ; 95 \% \mathrm{Cl}: 2.38-4.64$ \\
& Users were likely to be well-informed about symptoms & $\mathrm{OR}=2.63 ; 95 \% \mathrm{Cl}: 1.90-3.63$ \\
& Users were likely to have heard about sigmoidoscopy & $\mathrm{OR}=2.02 ; 95 \% \mathrm{Cl}: 1.50-2.74$ \\
\hline
\end{tabular}

A user is a person who answered YES to the question about using that specific source of information in the questionnaire

general practitioner and (5) specialists [29]. Older respondents were likely to obtain their information about CRC from general practitioners, specialists, newspapers and brochures. However, younger respondents and participants in a relatively good financial situation were likely to use the internet to gather information. Respondents who were well-informed about risk factors and symptoms were most likely to access their information on the internet. Respondents who had heard about the non-invasive screening method and colonoscopy were most likely to learn about them from general practitioners and other health workers, but in the case of sigmoidoscopy, the internet was the most characteristic source of information. Participants who had not heard about CRC were likely to be younger and see their physician relatively seldom.

Very few respondents considered their knowledge about CRC suitable. They were likely to be females with a relatively high level of educational attainment. However, a significant number of respondents (67.4\%) were open to obtaining more information. A previous survey found a nearly similar rate (60.0\%) [24]. Religious respondents and people who had not heard about CRC screening were more open to new information.

\section{Limitations}

Cross-sectional surveys do not permit causal generalizations. Another limitation of the study is the nonprobability sampling used, raising concerns about the occurrence of self-selection bias. We attempted to minimise this by collecting a sample that was representative with respect to age, sex and place of residence. It was people who saw their general practitioner who were recruited for this study; this could have caused bias on the following question: "How often do you see your doctor?". General practitioners and assistants were asked not to aid participants in completing the questionnaires so as not to influence their answers.

\section{Conclusions}

The decisive majority of respondents did not know the CRC screening guideline and did not have accurate information about CRC risk factors and symptoms. Furthermore, a significant number of respondents had not heard about CRC screening methods. This lack of information can result in a low rate of participation in CRC screenings, since adequate knowledge is essential for participation. Most of the respondents were open to new information. To broaden people's awareness of this topic, health promotion programmes should focus on males, relatively young people, those who have a relatively low level of educational attainment, and those who do not live in a county town and do not see their physician regularly. Health workers and the internet have a significant role in mediating information. Consequently, these sources of information should be strengthened.

\section{Additional file}

Additional file 1: Data were collected through self-made questionnaires. The questionnaire contains 19 questions (dichotomous questions, singleanswer multiple choice questions, multiple-answer multiple choice questions, and likert-type scales questions). (DOCX $28 \mathrm{~kb}$ )

\section{Abbreviations \\ CRC: Colorectal Cancer; FOBT: Faecal Occult Blood Test; M2-PK: pyruvate kinase isoenzyme type M2}

\section{Acknowledgments}

This project was supported by 23 general practitioners and their assistants.

\section{Availability of data and materials}

The datasets used and/or analysed during the current study are available from the corresponding author on request.

\section{Authors' contributions}

The study was designed by NG, DRK and IK. NG and DRK participated in the acquisition of data and performed the statistical analyses. NG prepared the draft of the paper. IK supervised the study, and participated in the interpretation of the data, and the drafting of the manuscript. All authors have read and approved the final version of this manuscript. 


\section{Ethics approval and consent to participate}

Ethical approval was granted by the Regional and Institutional Ethical Committee of University of Pecs, Hungary. Written informed consent was obtained from all participants.

\section{Consent for publication}

Not applicable.

\section{Competing interests}

The authors declare that they have no competing interests.

\section{Publisher's Note}

Springer Nature remains neutral with regard to jurisdictional claims in published maps and institutional affiliations.

\section{Author details}

${ }^{1}$ Institute for Translational Medicine, Medical School, and Doctoral School of Health Sciences, Faculty of Health Sciences, University of Pécs, Szigeti út 12, Pécs 7624, Hungary. ${ }^{2}$ Doctoral School of Health Sciences, University of Pécs, Pécs, Hungary. ${ }^{3}$ Department of Public Health Medicine, Medical School, University of Pécs, Pécs, Hungary.

Received: 2 November 2017 Accepted: 20 June 2018

Published online: 30 June 2018

\section{References}

1. The International Agency for Research on Cancer, GLOBOCAN 2012. France. http://globocan.iarc.fr. Accessed 28 Sept 2017.

2. Eurostat Statistics Explained. http://ec.europa.eu/eurostat/statistics-explained. Accessed 28 Sept 2017.

3. Péter Z, Zs T. A kolonoszkópia a vastagbélszűrés elsődleges módszere. Orv Hetil. 2009;150(7):299-304.

4. World Cancer Research Fund and American Institute for Cancer Research Food. Nutrition, physical activity, and the prevention of Cancer: a global perspective. Washington, DC: American institute for Cancer Research; 2007.

5. Zisman AL, Nickolov A, Brand RE, Gorchow A, Roy HK. Associations between the age at diagnosis and location of colorectal cancer and the use of alcohol and tobacco: implications for screening. Arch Intern Med. 2006; 166(6):629-34.

6. Boyle P, Langman JS. ABC of colorectal cancer: epidemiology. BMJ. 2000; 321(7264):805-8.

7. Lauby-Secretan B, Vilahur N, Bianchini F, et al. The IARC perspective on colorectal Cancer screening. N Engl J Med. 2018;378(18):1734-40.

8. Fitzpatrick-Lewis D, Ali MU, Warren R, Kenny M, Sherifali D, Raina P. Screening for colorectal Cancer: a systematic review and meta-analysis. Clin Colorectal Cancer. 2016;15(4):298-313.

9. Döbrőssy L, Kékes E, Döbrőssy B, Németh E. Szűrővizsgálatokról Szakembereknek. Országos Tisztiorvosi Hivatal: Budapest, Magyarország; 2010.

10. Ford JS, Coups EJ, Hay JL. Knowledge of colon cancer screening in a national probability sample in the United States. J Health Commun. 2006; 11(1):19-35.

11. McAlearney AS, Reeves KW, Dickinson SL, Kelly KM, Tatum C, Katz ML, Paskett ED. Racial differences in colorectal cancer screening practices and knowledge within a low-income population. Cancer. 2008;112(2):391-8.

12. Felsen CB, Piasecki A, Ferrante JM, Ohman-Strickland PA, Crabtree BF. Colorectal cancer screening among primary care patients: does risk affect screening behavior? J Community Health. 2011:36(4):605-11.

13. Koo JH, Leong RW, Ching J, et al. Knowledge of, attitudes toward, and barriers to participation of colorectal cancer screening tests in the AsiaPacific region: a multicenter study. Gastrointest Endosc. 2012;76(1):126-35.

14. Koo JH, Arasaratnam MM, Liu K, Redmond DM, Connor SJ, Sung JJ, Leong RW. Knowledge, perception and practices of colorectal cancer screening in an ethnically diverse population. Cancer Epidemiol. 2010;34(5):604-10.

15. Overholser L, Zittleman L, Kempe A, et al. Use of colon cancer testing in rural Colorado primary care practices. J Gen Intern Med. 2009;24(10): 1095-100.

16. Sanderson PR, Weinstein N, Teufel-Shone N, Martínez ME. Assessing colorectal cancer screening knowledge at tribal fairs. Prev Chronic Dis. 2011; $8(1): 16-25$.
17. Gregory TA, Wilson C, Duncan A, Turnbull D, Cole SR, Young G. Demographic, social cognitive and social ecological predictors of intention and participation in screening for colorectal cancer. BMC Public Health. 2011:14:38-48.

18. Döbrőssy L. Daganatok szűrése. Budapest, Magyarország: Országos Tisztiorvosi Hivatal; 2013

19. Choi KS, Jun JK, Lee HY, Hahm MI, Oh JH, Park EC, et al. Increasing uptake of colorectal cancer screening in Korea: a population-based study. BMC Public Health. 2010;10:265-73.

20. Wagner VC, Baio G, Raine R, et al. Inequalities in participation in an organized national colorectal cancer screening programme: results from the first 2.6 million invitations in England. Int J Epidemiol. 2011;40(3):712-8.

21. Lewis CL, Brenner AT, Griffith JM, Pignone MP. The uptake and effect of a mailed multi-modal colon cancer screening intervention: a pilot controlled trial. Implement Sci. 2008:3:32-9.

22. Leone LA, Reuland DS, Lewis CL, Ingle M, Erman B, Summers TJ, DuBard CA, Pignone MP. Reach, usage, and effectiveness of a Medicaid patient navigator intervention to increase colorectal Cancer screening, cape fear, North Carolina, 2011. Prev Chronic Dis. 2013;10:82-90.

23. Tseng TS, Holt CL, Shipp M, Eloubeidi M, Britt K, Norena M, Fouad MN Predictors of colorectal cancer knowledge and screening among churchattending African Americans and whites in the deep south. J Community Health. 2009;34(2):90-7.

24. Papanikolaou IS, Sioulas AD, Kalimeris $S$, et al. Awareness and attitudes of Greek medical students on colorectal cancer screening. World J Gastrointest Endosc. 2012:4(11):513-7.

25. Sessa A, Abbate R, Di Giuseppe G, Marinelli P, Angelillo IF, et al. Knowledge, attitudes, and preventive practices about colorectal cancer among adults in an area of southern Italy. BMC Cancer. 2008;8:171-9.

26. Berkowitz Z, Hawkins NA, Peipins LA, White MC, Nadel MR, et al. Beliefs, risk perceptions, and gaps in knowledge as barriers to colorectal cancer screening in older adults. Journal J Am Geriatr Soc. 2008;56(2):307-14.

27. Bidouei $\mathrm{F}$, Abdolhosseini $\mathrm{S}$, Jafarzadeh $\mathrm{N}$, et al. Knowledge and perception toward colorectal cancer screening in east of Iran. Int J Health Policy Manag. 2014;3(1):11-5.

28. Christou A, Thompson SC. Colorectal cancer screening knowledge, attitudes and behavioural intention among indigenous western Australians. BMC Public Health. 2012;12:528-43.

29. Domati F, Travlos E, Cirilli C, et al. Attitude of the Italian general population towards prevention and screening of the most common tumors, with special emphasison colorectal malignancies. Intern Emerg Med. 2009:4(3):213-20.

\section{Ready to submit your research? Choose BMC and benefit from:}

- fast, convenient online submission

- thorough peer review by experienced researchers in your field

- rapid publication on acceptance

- support for research data, including large and complex data types

- gold Open Access which fosters wider collaboration and increased citations

- maximum visibility for your research: over $100 \mathrm{M}$ website views per year

At BMC, research is always in progress.

Learn more biomedcentral.com/submissions 